\title{
Neurodevelopmental outcome at early school age of children born to mothers with gestational diabetes
}

\author{
A Ornoy, A Wolf, N Ratzon C Greenbaum, M Dulitzky
}

\begin{abstract}
Aims-To study the metabolic derangements in the second half of pregnancy caused by gestational diabetes, on the long term development of children.

Methods-The neuropsychological function of 32 school age children born to 32 mothers with well controlled gestational diabetes and 57 control children matched by age, birth order, and parental socioeconomic status was studied.

Results-There were no differences in head circumference and height, but the children born to diabetic mothers were heavier. The verbal IQ scores of index children below the age of 9 years were lower than those of control children. No differences were found between the groups in various sensory and motor functions and in the Touwen and Prechtl neurological test. The young index group children performed less well than controls in fine and gross motor functions, as observed on the Bruininks-Oseretzky test of motor proficiency. The scores of young children born to mothers with gestational diabetes were also lower than controls on the Pollack tapper test, and there were more index group children who scored abnormally on the parents' Conners questionnaire. No correlation was found between the performance of the index group children on various neurodevelopmental tests and the severity of perinatal complications. The differences tended to disappear with age.

Conclusions-Gestational diabetes, as a result of the metabolic abnormalities in the second half of pregnancy, induces long term minor neurological deficits which are more pronounced in younger children. There does not seem to be any direct relation between the appearance of congenital anomalies and neurodevelopmental outcome.
\end{abstract}

(Arch Dis Child Fetal Neonatal Ed 1999;81:F10-F14)

Keywords: gestational diabetes; pregnancy; IQ; neurological functions

Department of

Psychology

C Greenbaum

Sheba Medical Center Tel Aviv University

Israel

M Dulitzky

Correspondence to: Dr Asher Ornoy.

Accepted 1 February 1999
10-15 years, the prevalence of congenital anomalies among offspring of diabetic mothers has decreased. This reduction is directly related to the improvement of glycaemic control in early pregnancy. ${ }^{3}{ }^{67}$

Various studies have addressed the question of possible brain damage induced by diabetes during the second half of pregnancy, which may result in developmental disorders. Some neurological dysfunction is to be expected as the major developmental events of the cerebral cortex such as migration, differentiation, and layering of the cortical neurons, myelination, and synapse formation occur during the second half of pregnancy. ${ }^{12} 13$

In a recent study we found ${ }^{14}$ that when 10.5 day old rat embryos were cultured in serum obtained from diabetic patients, there was a high proportion of major congenital anomalies; serum from type 1 diabetic patients induced major congenital anomalies in $71 \%$ of the embryos. When serum from women with gestational diabetes was used as the culture medium, $53.3 \%$ of the embryos were malformed. This supports the view that diabetic metabolic abnormalities in gestational diabetes may affect the developing embryo. The observation that there is no increase in the prevalence of major congenital anomalies in children born to women with gestational diabetes can be explained by the fact that these metabolic changes occur when major organogenesis - with the exception of the brain - has already occurred. ${ }^{14}$

Stehbens et $a l^{15}$ examined children born to diabetic mothers when aged 1, 3, and 5 years. Small for gestational age children born to diabetic mothers had lower cognitive scores than controls. Similarly, Petersen et $a l^{16}$ found that the children of diabetic mothers who were small for gestational age had low verbal performance at 5 years, but that the children who did not sustain in utero growth retardation were normal. Cummins and Norrish ${ }^{17}$ did not find any differences in the cognitive scores of children born to diabetic mothers at 4.25-13.5 years compared with controls. Pearson and Gentz ${ }^{18}$ found no differences on these measures in children at 5 years of age born to diabetic mothers or to mothers with gestational diabetes. Rizzo et $a l^{19}$ did not find developmental delay in children born to diabetic mothers or to mothers with gestational diabetes, but found an inverse correlation between maternal blood $\beta$-hydroxy butyrate concentrations and scores on IQ tests for these children. In a later study Rizzo et $a l^{20}$ found a significant negative correlation between maternal second and third trimester $\beta$-hydroxy 
Table 1 Comparison of parental SES between index group and controls

\begin{tabular}{lllll}
\hline & $\begin{array}{l}\text { Maternal } \\
\text { education } \\
\text { (years) } \\
\text { Mean (SD) }\end{array}$ & $\begin{array}{l}\text { Paternal } \\
\text { education } \\
\text { (years) } \\
\text { Mean (SD) }\end{array}$ & $\begin{array}{l}\text { Family size } \\
\text { Mean (SD) }\end{array}$ & $\begin{array}{l}\text { No of rooms } \\
\text { Mean (SD) }\end{array}$ \\
\hline Control with gestational diabetes & $13.3(2.3)$ & $13.8(2.9)$ & $5.04(0.93)$ & $4.65(1.41)$ \\
Mothers wi & $12.7)$ & $12.6(2.5)$ & $5.39(0.95)$ & $4.87(1.67)$ \\
\hline
\end{tabular}

No differences between groups were found.

butyrate concentrations and IQ test scores in these children at 6 to 9 years of age. Their performance on the Bruininks-Oseretzky test, which measures fine and gross motor abilities, was also significantly impaired. Sells $e t a l^{21}$ found a higher incidence of developmental language delay among children born to diabetic mothers who started follow up late in pregnancy, and hence had poor glycaemic control.

Most of these studies, while providing important information on the sequelae of maternal diabetes, are limited by the fact that the children were examined at preschool age, while several important dysfunctions, such as attention deficit hyperactivity (ADHD) and learning difficulties can be diagnosed only at school age. Indeed, in a recent study ${ }^{22}$ we found that school age children born to diabetic mothers have normal cognitive scores, perform less well in fine and gross motor function, and have more inattention and hyperactivity when compared with matched controls. ${ }^{22}$

This study aimed to assess the development of early school age children born to mothers with gestational diabetes compared with matched controls, using several cognitive, sensory, motor and neurological tests. We also intended to correlate the neurological function of these children to the degree of perinatal complications.

\section{Methods}

The sample consisted of 32 children (41\% girls), born to 32 mothers with gestational diabetes during 1982-87 and 57 control children ( $46 \%$ girls) born to 57 non-diabetic healthy mothers matched for age, socioeconomic status based on parental education, occupation, family size and accommodation. ${ }^{23}$ (table 1). None of the control mothers had gestational diabetes. All children were born at the Sheba Medical Center, Tel Hashomer, near Tel-Aviv, Israel. All mothers of children from the index group were treated in the high risk pregnancy clinic at Sheba Medical Center. At that time only women with a history of diabetes in the family, or with previous gestational diabetes, or women with a previous birth of a child over $4.0 \mathrm{~kg}$, were tested for glucose tolerance during their pregnancy. Women with large fetuses in the current pregnancy or with glycosuria (all women were routinely screened for glyscosuria) were similarly treated. Of these women, all those with an abnormal test (190 $\mathrm{mg} \%$ glucose or more at 90 minutes, $165 \mathrm{mg}$ $\%$ or more at 120 minutes, 145 or more at 180 minutes, or with $105 \mathrm{mg} \%$ or more fasting glucose blood concentrations) were considered to have gestational diabetes. Most women were diagnosed in the second trimester of pregnancy and some in the third trimester. Once diag- nosed, a follow up fasting glucose was done once a week. Clinical follow up was carried out once every 2 weeks. Women with gestational diabetes were given low sugar diets. If fasting blood glucose was $110 \mathrm{mg} \%$ or more, or postprandial glucose was $140 \mathrm{mg} \%$ or more, they were treated with insulin.

Forty four women with gestational diabetes, all treated with insulin, were therefore recruited. Eleven women could not, or refused to, participate in the study. One additional child was born with multiple anomalies and died at 2 years of age, so was excluded from the study. The remaining pregnancies resulted in the birth of 32 children over 32 weeks of pregnancy weighing over $1500 \mathrm{~g}$ at birth and without major anomalies. The results of laboratory tests relating to the degree of glycaemic control-glucose blood concentrations, glycosuria, and ketonuria - are incomplete and are therefore not presented here. When studied, the average age of the children in the index group was 8.5 (SD 2.1) years, ranging from $5.2-12.1$ years (47\% young children, $5-8$ years of age; $53 \%$ older children, $9-12$ years of age). The corresponding figure for the control children was 8.3 (1.7), ranging between $5.5-12.2$ years, (5-8 years, $55 \% ; 9-12$ years, $45 \%)$. All were in normal schools.

We constructed our control sample by searching the birth records at the Sheba Medical Center for 1982-87, and by contacting parents by telephone. We found 67 children who lived up to $100 \mathrm{~km}$ from the hospital, and who were suitable to serve as matched controls. Of these, 32 parents (47\%), mostly from areas far from the hospital, found it too difficult to participate and we examined the remaining 35 children from areas close to the hospital. All had been delivered in Sheba Medical Center. To complete the control group, we also included 22 children from a nearby school of the same ages and socioeconomic status. These children were also born in Sheba Medical Center during the same years. The 22 children from the school and the other 35 children had background characteristics and outcome variables similar to those described below. This group of 57 control children also served us in a previous study on the outcome of children born to diabetic mothers. ${ }^{22}$ The control and index children were matched by age and school placement - all studying in normal schools - as well as by gestational age. They were also similar in terms of parental education, family size, and number of rooms at home (table 1).

The following tests were administered to each participating child:

- A complete medical and neurological examination

- The Touwen-Prechtl neurological examination for children with minor nervous dysfunction. ${ }^{24}$ Abnormal neurological findings on this test were scored, and a total score of 10 or more was considered abnormal-that is, pointing to some neurological impairment. ${ }^{25}$

- Evaluation of the cognitive score using the Wechsler Intelligence Scales for Children Revised (WISC-R, 1974) 
- Bender Visual Gestalt test ${ }^{26}$ for the evaluation of eye-hand coordination

- Goodenough Draw a Man test ${ }^{27}$

- Bruininks-Oseretsky Motor Development test $^{28}$ which examines the fine and gross motor development of children aged 4.514.5 years

- Southern California Integration Test $^{29}$ for the evaluation of children's sensory functioning. This test includes three subtests: manual form perception (MFP), finger identification (FI), and localisation of tactile stimuli (LTS). The test was carried out by an occupational therapist.

- Conners Abbreviated Parents-Teachers' Questionnaire for the diagnosis of inattention and hyperactivity ${ }^{30}$

- The Pollack tapper test ${ }^{31}$ to assess attention deficits. The child is asked to repeat a specific sequence of light blinks and auditory taps presented by the tester. The number, sequence, and duration of these stimuli is adapted according to the child's age. Children with attention deficit tend to obtain lower scores than those with a normal attention span.

- Achenbach's questionnaire for the measurement of behaviour ${ }^{32}$

- Home observation for measurement of environment questionnaire ${ }^{33}$

For each control or index child we filled out a detailed questionnaire related to pregnancy complications-gestational bleeding, hypertension, urinary tract infections, toxaemia, premature uterine contractions and pregnancy related hospital stays-and to perinatal complications - mode of delivery, birthweight in relation to gestational age, respiratory distress, hypoglycaemia and convulsions.

The first two assessments were carried out by a developmental paediatrician; the WISC-R, Bender, and Goodenough tests by a developmental psychologist, and the other assessments by an occupational therapist. In all cases the tester was blinded to the mother's diabetic status.

We compared index and control groups using two tailed group $t$ tests for each dependent variable. For comparison of the groups on various neurological tests, we used the Wilcoxon rank sum test (Mann Whitney test). Pearson correlation were calculated between the scores on the neurodevelopmental tests of the children and the perinatal complications. ${ }^{34}$

\section{Results}

Table 2 shows the results of the physical examination at birth and subsequently. There were no significant differences between the groups in birthweight; the gestational age of the control children was higher than that of the index children but the differences were not significant (table 2). Although there were more perinatal and neonatal complications among the index group children than in the controls - for example, hypoglycaemia, respiratory distress, developmental delay-the differences were not significant. There was a significant difference in the rate of Caesarean sections: $31 \%$ in the index group vs $7.1 \%$ in the controls.
Table 2 Comparison of physical evaluations between control children and children of mothers with gestational diabetes

\begin{tabular}{lcc}
\hline & $\begin{array}{l}\text { Controls } \\
\text { Mean (SD) }\end{array}$ & $\begin{array}{l}\text { Mothers with } \\
\text { gestational diabetes } \\
\text { (index) Mean (SD) }\end{array}$ \\
\hline $\begin{array}{l}\text { Gestational age } \\
\text { Birthweight (g) }\end{array}$ & $3254(582)$ & $3348(676)$ \\
$\begin{array}{l}\text { Head circumference } \\
\text { percentile }\end{array}$ & $48(24)$ & $47(22)$ \\
$\begin{array}{l}\text { Height percentile } \\
\text { Weight percentile }\end{array}$ & $44(30)$ & $49(25)$ \\
Weight/height $\left(\mathrm{kg} / \mathrm{mm}^{2}\right)$ & $44^{\star}(30)$ & $68(27)$ \\
\hline
\end{tabular}

Mean (SD).

^Significantly lower than mothers with gestational diabetes; $\mathrm{p}<0.05$.

Table 3 Comparison of cognitive scores on WISC-R, Draw a Man, and on Bender Gestalt test of control children and those born to mothers with gestational diabetes

\begin{tabular}{|c|c|c|c|c|}
\hline \multirow[b]{2}{*}{ Test } & \multicolumn{2}{|l|}{ Controls } & \multicolumn{2}{|c|}{$\begin{array}{l}\text { Mothers with gestational } \\
\text { diabetes (index) }\end{array}$} \\
\hline & $\begin{array}{l}\text { Young } \\
\text { Mean } \\
(S D)\end{array}$ & $\begin{array}{l}\text { Old } \\
\text { Mean } \\
\text { (SD) }\end{array}$ & $\begin{array}{l}\text { Young } \\
\text { Mean } \\
\text { (SD) }\end{array}$ & $\begin{array}{l}\text { Old } \\
\text { Mean } \\
\text { (SD) }\end{array}$ \\
\hline IQ & ${ }^{\star} 121(8)$ & $116(12)$ & $111(14)$ & 115 (13) \\
\hline Verbal & ${ }^{\star} 115$ (11) & $113(13)$ & $107(11)$ & $109(12)$ \\
\hline Performance & $123(11)$ & $117(12)$ & $114(17)$ & $119(15)$ \\
\hline Bender (\%) & $\star 48(25)$ & $\star 49(29)$ & $32(25)$ & $32(31)$ \\
\hline Draw a man & $99(17)$ & $98(17)$ & $97(16)$ & $94(13)$ \\
\hline
\end{tabular}

*Significantly higher than young and/or old index group children; $\mathrm{p}<0.05$.

Table 4 Comparison of motor development (Bruininks-Oseretzky) in control children and those born to mothers with gestational diabetes

\begin{tabular}{lcl}
\hline & $\begin{array}{l}\text { Mothers with } \\
\text { Gestational } \\
\text { diabetes (index) } \\
\text { Mean (SD) }\end{array}$ \\
Bruininks test & $\star 128(23)$ & $113(28)$ \\
\hline Total, young & $127(18)$ & $131(26)$ \\
Total, old & $\star 59.2(130)$ & $52.1(15.5)$ \\
Gross motor, young & $66.8(10.3)$ & $61.8(14.7)$ \\
Gross motor, old & $\star 53.4(9.7)$ & $45.9(11.6)$ \\
Fine motor, young & $46.9(7.9)$ & $52.1(9.1)$ \\
Fine motor, old & & \\
\hline
\end{tabular}

*Significantly higher than index group children; $\mathrm{p}<0.05$.

Furthermore, $12.5 \%$ of the index group children stayed an additional year in the kindergarten compared with only $5.4 \%$ of controls. On examination, the body weight of the children born to mothers with gestational diabetes was greater than that of controls (table 2). A similar finding was observed in the weight to height ratio (table 2). There were no differences in head circumference and height. A non-significant positive $(r=0.16)$ correlation was found in the index group children between birthweight and the weight at examination.

COGNITIVE AND NEUROLOGICAL DEVELOPMENT Table 3 shows the WISC-R, Goodenough Draw a Man, and Bender tests for the index and control children. The general IQ scores of the WISC-R test, and the verbal scores, were higher in the young controls than in the young index group children. The scores on the Bender test (in percentiles) were significantly lower in the young and older index groups. No differences were observed between the groups in the Goodenough Draw a Man test (table 3).

Results of the motor assessments of the children are given in table 4 . Young index group children had significantly lower scores on the 
Table 5 Comparison of Conners questionnaire with Pollack tapper test between control children and those born to mothers with gestational diabetes before and after 8 years of age

\begin{tabular}{|c|c|c|c|c|}
\hline & \multicolumn{2}{|l|}{ Young } & \multicolumn{2}{|l|}{ Old } \\
\hline & $\begin{array}{l}\text { Controls } \\
\text { Mean (SD) }\end{array}$ & $\begin{array}{l}\text { Index } \\
\text { Mean (SD) }\end{array}$ & $\begin{array}{l}\text { Controls } \\
\text { Mean (SD) }\end{array}$ & $\begin{array}{l}\text { Index } \\
\text { Mean (SD) }\end{array}$ \\
\hline Conners parents' questionnaire & $7.9(4.3)$ & $8.0(6.5)$ & $7.0(4.3)$ & $6.8(6.3)$ \\
\hline Pollack - general & $28.0(3.2)$ & $19.0(12.4)$ & $30.3(6.9)$ & $29.6(10.5)$ \\
\hline Pollack - sound & $\star 14.8(65)$ & $10.6(6.6)$ & $15.6(3.6)$ & $14.9(5.0)$ \\
\hline Pollack — visual & $\star \star 13.2(2.0)$ & $7.7(5.9)$ & $14.7(3.4)$ & $14.1(5.4)$ \\
\hline
\end{tabular}

*Significantly higher than index group; $\mathrm{p}<0.05$

${ }^{\star}{ }^{\star}$ Significantly higher than index group; $\mathrm{p}<0.01$.

Bruininks-Oseretsky fine and gross motor scores compared with the controls. This was not so in children aged 9 years or older, and the average scores for both age group children were therefore similar in the controls and index children (table 4). A direct correlation was found between the weight of the young index children and their failure in gross motor functions. No significant correlation was found between weight and fine motor functions.

No significant differences between the index and control groups were observed in any of the three subtests of the Southern California sensory integration test (MFP, FI, and LTS) that were designed to reflect sensory-motor functioning (results not shown).

Children born to mothers with gestational diabetes were no different from controls in the number of soft neurological signs in the Touwen and Prechtl examination (results not shown).

The results of Conners Questionnaire and of the Pollack tapper test are shown in table 5. There were no differences between the groups in the average scores for inattention and hyperactivity on the parents' Conners Questionnaire, but five index group children $(16 \%)$ had abnormal scores (above 14) compared with only two controls $(3.5 \%)$. This difference was not significant (Wilcoxon test, $\mathrm{p}=0.06$ ). Children of the index group below the age of 9 years had significantly lower scores on the Pollack tapper test compared with controls on both sound and visual tests. The differences disappeared in the older age group (table 5).

There were no significant differences between the groups in the Achenbach questionnaire, but there were several measures where the difference between groups was close to significant, such as internalising events (results not shown).

The home observation for measurement of the environment was no different between the groups, implying that the children were raised in similar conditions.

No correlation was found between the medical status-for example, hypoglycaemia, convulsions - of the newborn infants and outcome of any of the associated variables in the index or control groups.

Due to incomplete data on maternal blood glucose concentrations, glycosuria, and acetonuria in the index group mothers, we did not study the possible correlation between developmental outcome and degree of maternal glycaemic control.

\section{Discussion}

School age children younger than 9 years, born to mothers with gestational diabetes, had a higher rate of attention deficit, lower cognitive scores, and lower gross and fine motor achievements than matched control children. These differences were highest in the young children and tended to diminish with age. No correlation was found between several measures related to perinatal and neonatal complications and neurodevelopmental outcome.

Studies describing the development of children born to diabetic mothers, or to mothers with gestational diabetes, usually report normal on physical and neurological development. ${ }^{16}{ }^{18-2135}$ We found that many neurological functions were poorer in children born to mothers with gestational diabetes compared with controls.

More young index group children had subnormal scores on the Pollack tapper test and more had abnormal scores on Conners questionnaire than controls. These tests are good predictors for ADHD, ${ }^{25}$ implying that ADHD and perhaps learning disabilities may be more common among children born to mothers with gestational diabetes. However, the differences in the results of these tests tended to disappear in the older index group children, a tendency that is rare in children with ADHD or with learning disabilities. Lambert and Sandoval ${ }^{35}$ found a high prevalence of pre- and perinatal complications in children with ADHD, including more health problems in their mothers, when compared with control (normal) children. We already have described a high prevalence of minor neurological dysfunction among children born to diabetic mothers compared with control children, ${ }^{22}$ but in that study the differences among the groups did not lessen with age.

Soft neurological signs may be a sign of mild, non-specific brain damage. ${ }^{37}$ Variability in muscle tone (hypertonicity or hypotonicity) may cause delayed or abnormal motor development, ${ }^{37} 38$ and we saw this in the young index group children. Older index children may be able to compensate for slight motor impairment, and their achievement in the tests may be normal, as is their daily function. The gap in the maturation of the central nervous system in the index group children compared with that of the controls may have decreased with age, so that older index children functioned closer to controls. If this is the case, even higher gaps in preschool children born to diabetic mothers might have been expected, but we did not test this.

Young and older index group children weighed more than control children. We have already observed a similar finding among school age children born to mothers with type I or type II diabetes. ${ }^{22}$ Similar results were reported by Rizzo et $a l^{20}$ and by Metzger et $a \beta^{4}$ in children born to diabetic mothers. The increased weight of infants born to diabetic mothers or to mothers with gestational diabetes observed in many studies is probably due to fetal hyperinsulinism, which abnormally 
increases the number of fat cells. ${ }^{38}$ This may also be the trigger for overweight in childhood.

A direct correlation between birthweight and weight at examination would be expected, but we found no such correlation in our study as the birthweight of our index children did not differ from that of controls.

We conclude that gestational diabetes, as a result of the metabolic abnormalities in the second half of pregnancy, induces long term minor neurological deficits which are more pronounced in the younger children. This implies that, as these neurodevelopmental changes are related to diabetic metabolic factors in the second half of pregnancy, there is no direct relation between the appearance of congenital anomalies and the neurodevelopmental outcome. However, our group is relatively small, and our results need further corroboration.

This study was supported by Grant No $032-4660$ from the Israeli Ministry of Health.

1 Eskes TK, Mooij PN, Steegers-Theunissen, RP, Lips JP Pasker-de Jong, PC. Pregnancy care and prevention of birth defects. F Perinat Med 1992;20:253-65.

2 Goto MP, Goldman AS. Diabetic embryopathy. Curr Op Ped 1994;6:486-91.

3 Hod M, Diamant YZ. The offspring of a diabetic mother-short and long range implications. Israel f Med Sci 1992;28:81-6.

4 Miller E, Hare JW, Cloherty JP, et al. Elevated maternal hemoglobin Alc in early pregnancy and major congenital anomalies in infants of diabetic mothers. $N$ Engl $尹 \mathrm{Med}$ 1981;304: 1331-4.

5 Mills JL, Baker L, Goldman AS. Malformations of infants of diabetic mothers occur before the 7 th gestational week: diabetic mothers occur before the 7 th gestational
Implications for treatment. Diabetes 1979;28:292-3.

6 Mills JL. Malformations in infants of diabetic mothers. Teratology 1982;25:285-394.

7 Mills JL, Knopp RH, Simpson JL, et al. NIHHD and diabetes in early pregnancy study: Lack of relation of increased malformation rates in infants of diabetic mothers to glycemic control during organogenesis. $N$ Engl f Med 1991;318:671-6.

8 Miodovnik M, Mimouni F, St. John Dignan P. Major malformations in infants of IDDM women: Vasculopathy and early first-trimester poor glycemic control. Diabetes Care 1988; 11:713-18.

9 Blumenthal SA, Abdul-Karim W. Diagnosis, classifications, and metabolic management of diabetes in pregnancy: Therapeutic impact of self-monitoring of blood glucose and of newer methods sefinsulitoring of blood glucose Surv 1987;42:593-603.

10 Cordero L, London MB. Infants of the diabetic mother. Diabetes in pregnancy 1993;20: 635-48.

11 Leslie RDG, Pyke DA, John PN, White JM. Haemoglobin Alc in diabetic pregnancy. Lancet 1978; ii:958-62.

12 Ornoy A. Is the developing brain responsive to external stimulation? In Tamir D, ed. Stimulation and intervention in infant development. Freund's. 1986: 316-18.

13 Dobbing J, Sands J. Quantitative growth and development of human brain. Arch Dis Child 1973;48:757-67.
14 Ornoy A, Zaken V, Abir R, Yaffee P, Raz I. Effects on rat embryos of culture in serum of women with gestational embryos of culture in serum of women
diabetes. Reprod Toxicol 1995; 9:643-51.

15 Stehbens JA, Baker GL, Kitchell M. Outcome at age 1, 3 and 5 years of children born to diabetic women. $A m \mathcal{F}$ Obstet Gynecol 1977;127: 408-15.

16 Petersen BM, Pedersen SA, Greisen G, et al. Early growth delay in diabetic pregnancy: Relation to psychomotor development at age 4. BMF 1988;296:598-600.

17 Cummins M, Norrish M. Follow-up of children of diabetic mothers. Arch Dis Child 1980; 55:259-64.

18 Persson B, Gentz J. Follow-up of children of insulindependent and gestational diabetes mothers. Acta Pediatr Scand 1984; 73:349-58.

19 Rizzo TA, Metzger BE, Burns WJ, Burns K. Correlations between antepartum maternal metabolism and intelligence of offspring. N Engl f Med 1991;325: 911-16.

20 Rizzo TA, Dooley SL, Metzger BE, Cho NH, Ogata ES, Silverman BC. Prenatal and perinatal influences on longterm psychomotor development in offspring of diabetic term psychomotor development in offspring of

21 Sells CJ, Robinson NM, Brown Z, Knopp RH. Long-term developmental follow-up of infants of diabetic mothers. $\mathcal{F}$ Pediatr 1994;125:59-517.

22 Ornoy A, Ratzon N, Greenbaum C, Peritz E, Soriano D, Dulitzky M. Neurobehavior of school-age children born to diabetic mothers. Arch Dis Child 1998;79:F94-F9.

23 Kark SL, Peritz E, Shiloh A, Slome C. Epidemiological analysis of the hemoglobin picture in parturient women of Jerusalem. Am ₹ Publ Health 1964;54:947-51.

24 Touwen BCL, Prechtl HFR. The neurological examination of the child with minor nervous system dysfunction. In: Clinics in Developmental Medicine. London: Heinemann, 1978: 1-105.

25 Ornoy A, Ariel L, Tennenbaum A. Inattention, hyperactivity and speech delay at 2-4 years of age as a predictor for

26 Koppitz ME. The Bender-Gestalt test for young children (Vol II). NewYork: Grune \& Shatton, 1975.

27 Harris DB. Measuring the psychological maturity of children: a revision and extension of the Goodenough draw a man test. New York: World Book Co, 196

28 Bruininks RH. Oseretsky Test of Motor Proficiency. Circle Pines, Minnesota: American Guidance Service, 1978.

29 Ayres AJ. Sensory Integration and Praxis Test. Los Angeles: Western Psychological Services, 1989.

30 Goyette $\mathrm{CH}$, Conners C, Ulrich RF. Normative data on revised parent and teacher rating scales $\mathcal{f}$ Abnormal Child Psychol 1978; 6:231-6.

31 Pollack M, Tuchler H. The Pollack tapper. An apparatus for the identification and differential diagnosis of reading in school children. The Head Teacher's Review, 1982.

32 Achenbach TM. Manual for the child behavior profile. University of Vermont Department of Psychiatry, VT. 1983.

33 Caldwell BM. Instruction manual inventory for infant home observation for measurement of environment). University of Arkansas press, Little Rock, Arkansas, 1970.

34 Beyer BH. Handbook of tables for probability and statistics. 2nd edn. New York: The Chemical Rubber Co, 1968.

35 Metzger BE, Silverman B, Freinkel N. Amniotic fluid insulin concentration as a predictor of obesity. Arch Dis Child 1993;65:1050-2.

36 Lambert NM, Sandoval J. The prevalence of learning disabilities in a sample of children considered hyperactive. f Abnormal Child Psychol 1980;8:33-50.

37 Smith TR. Impaired motor skill (clumsiness) in otherwise normal children: a review. Child Care Health and normal children: a review.

38 Hertzig ME, Shapiro T. The assessment of non-focal neurological signs in school aged children. In: Tapper D, ed. Soft
Neurological Signs. New York: Grune \& Stratton, 1987: $71-94$.

39 Silverman BL, Landsberg L, Metzger BE. Fetal hyperinsulinism in offspring of diabetic mothers. Ann NY Acad Sci 1993; 699:36-45. 